\title{
Histological and Histomorphometric Study of the Effect of Strontium Ranelate on the Healing of One-Wall Intrabony Periodontal Defects in Dogs
}

\author{
Enas Ahmed Elgendy ${ }^{1 *}$ and Malak Yousef Mohamed Shoukheba ${ }^{2}$
}

${ }^{1}$ Lecturer of Oral medicine, Periodontology, Oral Diagnosis and Radiology Department, Faculty of Dentistry, October 6 University, Egypt ${ }^{2}$ Lecturer of Oral Medicine, Periodontology, Oral Diagnosis and Radiology Department, Faculty of Dentistry, Tanta University, Egypt

\begin{abstract}
Background: Periodontal regeneration aims at the restitution of supporting periodontal tissues lost due to periodontal diseases. With an aim of improving bone regeneration, strontium ranelate and related compounds were developed and have become increasingly popular in osteoporosis treatment. The aim of the present study was to evaluate the effect of the strontium ranelate $2 \%$ gel on the regeneration of the surgically created intrabony defect in dogs.

Methods: One-wall intrabony defects $(4 \times 6 \mathrm{~mm})$ were surgically created in the mesial aspect of second premolars bilaterally (split mouth study) in 10 dogs. Each intrabony defect underwent one of 2 treatment modalities: placebo gel (methyl cellulose gel)/collagen sponge (control site, group I) or strontium ranelate gel/collagen sponge (experimental site, group II). The animals were sacrificed with an overdose of anesthesia at 3 months and block sections of the defects were collected for histological and histometric analysis.

Results: Clinical healing progressed uneventfully in general, no visible adverse reactions. Strontium treated group (group II) demonstrated a significantly higher regeneration of the attachment apparatus in the form of newly formed bone, cementum and little amount of connective tissue adhesion $(3.89 \pm 0.09,3.42 \pm 0.75,0.27 \pm 0.02$ respectively) than the control group $(1.17 \pm 0.63,1.75 \pm 0.07,1.26 \pm 0.05$ respectively $)(P<0.001)$. There was also significant differences between the two treatment modalities in the amount of epithelial down growth where control treated group show significant amount of epithelial down growth $(P<0.01)$.
\end{abstract}

Conclusion: It was concluded that, strontium ranelate $2 \%$ gel appears to be safe and may support periodontal wound healing/regeneration in intrabony periodontal defects without complications.

Keywords: Periodontal regeneration; Intrabony defect; Strontium ranelate

\section{Introduction}

The ultimate goal of periodontal therapy is not only the removal of the etiologic factors but also the regeneration of destroyed periodontal tissue [1]. Therapeutic approaches involve various modalities to arrest progression of periodontal tissue destruction, as well as regenerative techniques intended to restore structures destroyed during the disease process [2].

Strontium ranelate (SrRan) and related compounds have become increasingly popular in preventing and treating osteoporosis [3]. In vitro studies revealed that SrRan has an anabolic and antiresorptive activity, which increase both the collagen and non-collagen protein synthesis [4,5], enhance pre-osteoblast differentiation [6,7], inhibit osteoclast differentiation, and function $[8,9]$.

In normal adult mice, SrRan (200-1800 mg/kg/day, 104 weeks) administration increased vertebral bone formation and decreased bone resorption, which resulted in increased bone mass [10]. The administration of SrRan in normal rats $(225-900 \mathrm{mg} / \mathrm{kg} /$ day, i.e., 0.88 to $3.51 \mathrm{mmol} \mathrm{Sr} / \mathrm{kg} /$ day, 104 weeks) increased trabecular thickness and number and decreased trabecular separation in the tibial metaphysis, indicating that SrRan increased bone formation and decreased bone resorption at the metaphyseal bone level. This positive effect of SrRan on bone mass is associated with increased, plasma alkaline phosphatase activity, which is compatible with a bone-forming activity of SrRan [11].

Additionally, SrRan exerts beneficial effects on bone mass and strength as observed by Buehler et al. [12] in normal adult monkeys
(Macaca fascicularis) where SrRan (0.39-2.91 mmol Sr/kg/day, 6 months) was found to decrease bone resorption in the alveolar bone, an active site of bone remodeling, as assessed by histomorphometric analysis of osteoclast surface and number.

The purpose of this study was to evaluate the regenerative potential of SrRan on the treatment of one wall-intrabony defect in dogs.

\section{Materials and Methods}

\section{Animal selection}

A total of 10 adult male mongrel dogs weighing from $20-25 \mathrm{~kg}$ were selected from Physiology Department, Faculty of Medicine, Tanta University to be used in this study. The animal had intact dentition with healthy periodontium. The animals were fed a soft diet throughout the study to reduce the chance of mechanical interference with healing during food intake.

*Corresponding author: Dr. Enas Ahmed Elgendy, Lecturer of Oral medicine Periodontology, Oral Diagnosis and Radiology Department, Faculty of Dentistry, October 6 University, Egypt, E-mail: enaselgendy2005@yahoo.co.uk

Received November 06, 2012; Accepted December 26, 2012; Published December 28, 2012

Citation: Elgendy EA, Shoukheba MYM (2012) Histological and Histomorphometric Study of the Effect of Strontium Ranelate on the Healing of One-Wall Intrabony Periodontal Defects in Dogs. J Cytol Histol 3: 161. doi:10.4172/2157-7099.1000161

Copyright: (c) 2012 Elgendy EA, et al. This is an open-access article distributed under the terms of the Creative Commons Attribution License, which permits unrestricted use, distribution, and reproduction in any medium, provided the original author and source are credited. 


\section{Gel preparation}

Seven grams of methyl cellulose powder were dissolved in $100 \mathrm{ml}$ of boiled water to make the methyl cellulose gel. 2 gram strontium ranelate powder (Les Laboratoires Servier Industrie, 905, route de Saran, 45520 Gidy France) was dissolved in water and mixed into the methyl cellulose gel to make the SR gel that was sterilized in the autoclave at $110^{\circ} \mathrm{C}$ for 20 minutes.

\section{Surgical protocol}

The animals were anaesthetized using sodium thiopental I.V (12 mgkg). The surgical sites were disinfected with $10 \%$ povidine-iodine solution $1 \%$ titratable iodine. Bilateral mandibular first premolars were extracted prior to experimental surgery and the extraction sites were allowed to heal for 2 months. After healing buccal mucoperiosteal flaps were elevated, and one-wall intrabony defects $(4 \times 6 \mathrm{~mm})$ were surgically created with burs in the mesial aspect of second premolars bilaterally (split mouth study) (Figure 1). Two reference notches were created with a round bur on the root surfaces one at crest of the alveolar bone (N1) and another one at the base of the defect (N2). The root surfaces were carefully scaled, planned, flushed with sterile saline, and then dried with sterile gauze.

Each intrabony defect underwent one of two treatment modalities: placebo gel (methyl cellulose gel/collagen sponge (control site group I) or strontium ranelate gel/collagen sponge (experimental site group II). A sterile collagen sponge was cut into $4 \times 4 \mathrm{~mm}$, and soaked in 1 $\mathrm{ml}$ of strontium ranelate gel, or placebo gel according to the treatment modality. The soaked sponges were fitted into the created defects, and closure of the wound areas were performed by interrupted interdental suture. All of the surgical procedures were done by the same clinicians (E.E. \& M.S.).

\section{Postsurgical care}

After the operative procedures the dogs received Acupan I.M every 12 hours for pain control for 2 days. Intramuscular administration of antibiotics, Tetracycline HC (Terramycine retard $125 \mathrm{mg}$ intramuscular) in the first two days postoperatively after that mixed with dog's food for 7 days. The dogs were kept in separate cages, and a daily topical application of $0.12 \% \mathrm{CHX}$ solution during the healing period was performed. The animals were observed daily until suture removal and at least twice weekly thereafter.

\section{Histopathologic examination}

The animals were sacrificed with an overdose of anesthesia for histological examinations and histometric analysis at 3 months postoperatively.
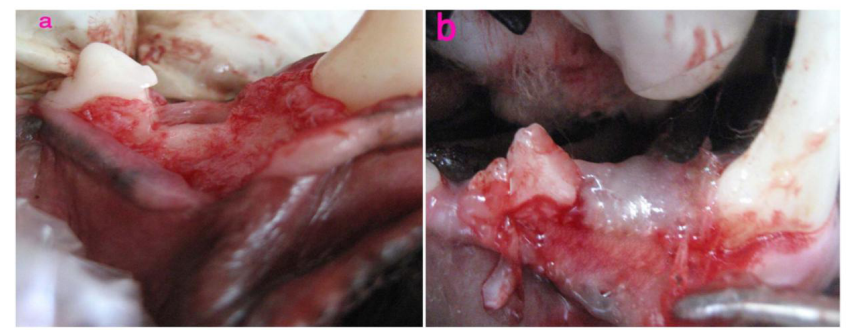

Figure 1: a) Clinical photograph showing surgically created 1-wall intrabony defect on the mesial aspect of the second mandibular premolar. b) The defect filled with collagen soaked in strontium ranelate gel.

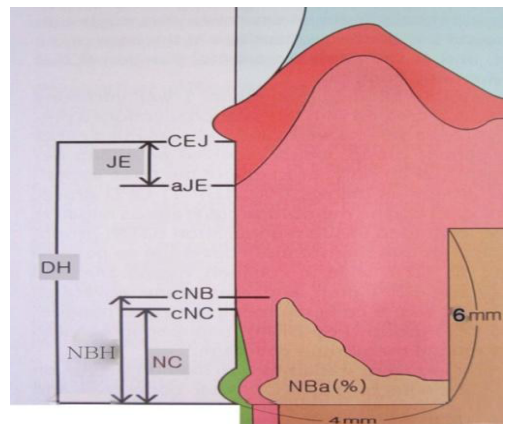

๙. Olympus BX50, Optical Co. LTD, Japan $\quad \delta$ : C5060WZ, Sony Electronic Inc., Tokyo, Japan

Figure 2: Schematic graph representing parameters for histometric analysis $\mathrm{NBH}=\mathrm{New}$ Bone Height, $\mathrm{cNC}=$ coronal extension of the newly formed cementum, cNB= coronal extension of Newly formed Bone , $\mathrm{DH}=$ Defect Height , JE= Junctional Epithelial, NC=New Cementum, NBa=New Bone area.

The treated experimental mandibular teeth (20 defects) with the surrounding bone were dissected free mesially and distally, fixed in $10 \%$ formalin for 10 days, decalcified in EDTA, dehydrated in ascending grades of ethanol $(70 \%, 80 \%, 90 \%, 100 \%)$ and cleared with xylene. Specimens were then kept in paraffin wax. Paraffin-embedded tissues were serially cut mesio-distaly with rotary microtome at $5 \mu \mathrm{m}$ thickness. The sections were then placed on glass slides and incubated overnight at $60^{\circ} \mathrm{C}$, after which they were rehydrated in xylene, rinsed in ethanol, and then water. The slides were stained with basic hematoxylin stain and counterstained with eosin for contrast and evaluation.

\section{For histometric analysis}

The histometric analysis included the study of 10 sections in each group using the image analysis software (Image ware, Image 1.3-1b, USA). The histologic sections were photographed and digitized with a light microscope $\delta$ (Olympus BX50, Optical Co. LTD, Japan) coupled to a digital camera $\delta \delta$ (C5060WZ, Sony Electronic Inc., Tokyo, Japan), at a lens magnification of $\times 25$ that's connected to a monitor and a personal computer, using the crest of the alveolar bone and the root notch as reference points [13] (Figure 2). The histometric parameters were:

-Linear measurements were performed after verification of anatomical landmarks at high magnification, and by outlining the borders of the various structures with a mouse cursor.

1. The Defect Height (DH): the distance between the base of the coronal notch (alveolar crest) and the base of the apical notch in millimetres.

2. Junctional Epithelial Migration (EDG): the distance from the base of the coronal notch (alveolar bone crest) to the apical extension of the junctional epithelium.

3. Cementum Regeneration (NC): the distance from the base apical notch to the coronal extension of newly formed cementum on the root surface.

4. Alveolar Bone Regeneration (NB): the distance from the base of the apical notch to the coronal extension of the newly formed alveolar bone.

5. Connective Tissue Adhesion (CT): the distance from the apical extension of the junctional epithelium to the coronal extension of the new cementum.

All of the histopathological and histometric studies were done 
Citation: Elgendy EA, Shoukheba MYM (2012) Histological and Histomorphometric Study of the Effect of Strontium Ranelate on the Healing of OneWall Intrabony Periodontal Defects in Dogs. J Cytol Histol 3: 161. doi:10.4172/2157-7099.1000161

by the same histopathologist who was masked to the treatment renderd.

\section{Statistical analysis}

The means and standard deviations of the experimental and control data $(\mathrm{n}=10)$ were obtained from the measurements taken from the central section of each defect. The Wilcoxon signed-rank test was used to compare the experimental and control data using a statistical software program SPSS ver. 17.0 (SPSS Inc., Chicago, IL, USA), with the level of significance set at $5 \%$.

\section{Results}

\section{Histologic observations}

Clinical healing progressed uneventfully in general, no visible adverse reactions including root exposure, infection and suppuration were observed until the time point of sacrifice 3 months after surgery.

Three months postoperatively shows nearly complete periodontal regeneration with a marked amount of newly formed bone and
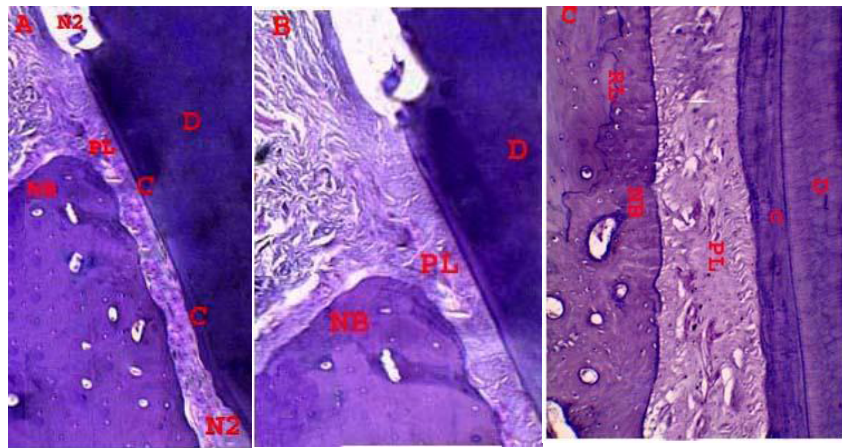

Figure 3: (a)Histopathology of tested group (strontium ranelate gel) section showing marked newly bone formation (NB) above the notch (N2), Thin layer of acellular cementum at the coronal area of the defect and thick layer at the N2 (H\&E . OMX40). (b) High power of tested group shows periodontal ligament with densely arranged good perpendicularly inserted fibers $(P L)$ into the cementum C and newly formed bone( NB) (H\&E, OMX100). (c) reversal line was also observed $(R L)$, periodontal ligament with densely well arranged good perpendicularly inserted fibers $(\mathrm{PL})$ into the thick cementum layer near from the N2 (H\&E, OMX200).

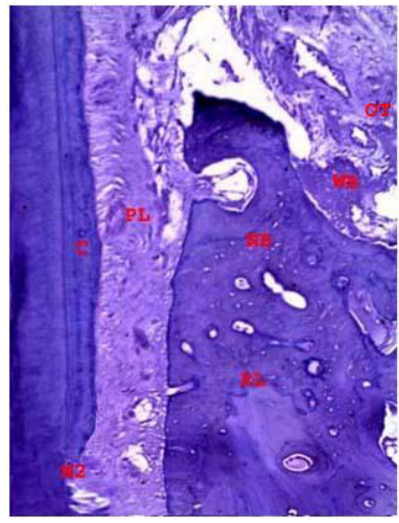

Figure 4: Another histopathology of tested treated group (strontium ranelate gel) section showing marked Newly Bone formation (NB) above the notch (N2), Thick layer of acellular cementum all over the defect, functionally oriented Periodontal Ligament Fiber (PL). Area of woven bone and osteoid tissue also observed. (H\&E OMX100).

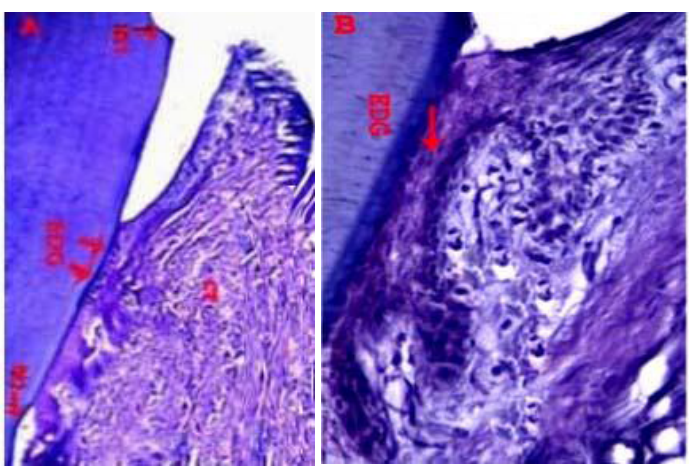

Figure 5: a) Histopathology of control treated group section showing epithelial down growth along the root surface (EDG), connective tissue adhesion ( CT) , with no bone formation (H\&E .OMX40). b) High power of epithelial down growth (EDG) N1, N2 (reference notches) (H\&E, OMX100).

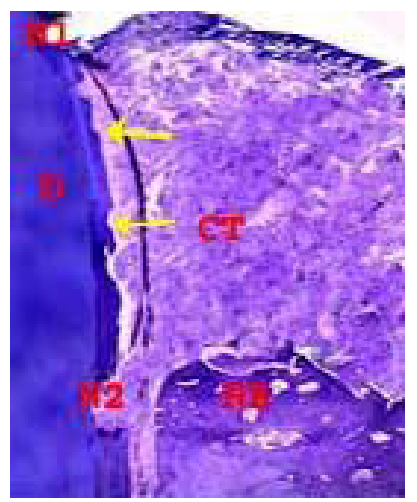

Figure 6: Another histopathological section of the control group show minimal bone (NB) reaching slightly coronal to the notch area (N2). Area of root resorption (yellow arrows) was also observed. No epithelial down growth was observed in this section but healing by Connective Tissue attachment (CT) (H\&E, OMX40).

cementum connecting with newly regenerated functionally oriented PDL groups of fibers (PDL) were observed only in the experimental group (Figures 3 and 4). A thicker granulation tissue covers the regenerated bone, woven bone and osteoid tissue are seen in the granulation tissue proximal to the newly regenerated bone (Figures 3 and 4). New cementum grew prominently along the root surface in the strontium treated group compared to the control treated group, its thickness was thicker at the notch area, becoming thin coronally (Figure $3 \mathrm{a}$ ), in another section the newly formed cementum is uniformly thick all over the defect (Figure 4).

Whereas control treated specimens showed limited bone regeneration reaching slightly above the notch $(\mathrm{N} 2)$ with poor-oriented periodontal fibers were observed. A newly regenerated flat interdental papilla containing disoriented interlacing connective tissue fiber and PDL fibers covers the regenerated bone, the surface of the regenerated papilla is epithelized (Figure 6). Epithelial down growth along the root was also observed in the majority of specimens (Figure 5). Root resorption was observed only in one specimen of the control treated group (Figure 6).

\section{Histometric analysis}

The histometric results of Defect Height (DH), Epithelial Down Growth (EDG), New Cementum (NC), New Bone (NB) and 
Citation: Elgendy EA, Shoukheba MYM (2012) Histological and Histomorphometric Study of the Effect of Strontium Ranelate on the Healing of OneWall Intrabony Periodontal Defects in Dogs. J Cytol Histol 3: 161. doi:10.4172/2157-7099.1000161

\begin{tabular}{|l|c|c|c|}
\hline Tested parameters & $\begin{array}{c}\text { Group I } \\
\mathbf{N = 1 0}\end{array}$ & $\begin{array}{c}\text { Group II } \\
\mathbf{N = 1 0}\end{array}$ & $\begin{array}{c}\text { Wilcoxon signed- } \\
\text { rank test P-value }\end{array}$ \\
\hline Defect height & $5.82 \pm 0.16$ & $5.79 \pm 0.13$ & 0.684 \\
\hline Junction epithelial down growth & $0.87 \pm 0.46$ & $0.0 \pm 0.0$ & $0.002^{* *}$ \\
\hline Connective tissue adhesion & $1.26 \pm 0.05$ & $0.27 \pm 0.02$ & $0.000^{*+*}$ \\
\hline New cementum & $1.75 \pm 0.07$ & $3.42 \pm 0.75$ & $0.000^{*+*}$ \\
\hline New bone & $1.17 \pm 0.63$ & $3.89 \pm 0.09$ & $0.000^{*+*}$ \\
\hline
\end{tabular}

Table 1: Histometric analysis of the measured parameters in the experimenta (strontium ranelate gel) and control groups (mean \pm standard deviation in $\mathrm{mm}$ ).

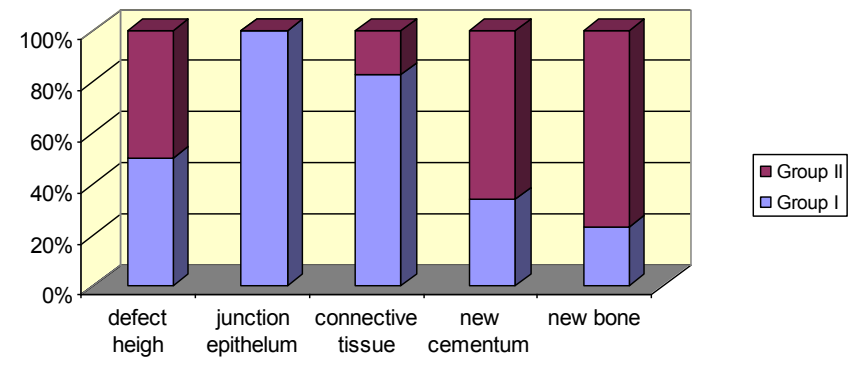

Figure 7: The effect of treatments on the Histomorphometric measurments of the one wall intrabony defects after healing in dogs.

Connective Tissue Attachment (CTA), are given in Table 1 and Figure 7.

Data analysis showed no significant differences between the treatment groups regarding the initial defect height $(5.82 \pm 0.16,5.79 \pm$ 0.13 for group I \& II respectively) $(\mathrm{P}=0.684)$.

The inter group analysis demonstrated that strontium treated group showed a superior and significant height of new bone, new cementum extension and little amount of connective tissue adhesion $(3.89 \pm 0.09$, $3.42 \pm 0.75,0.27 \pm 0.02$ respectively) than the control group (1.17 \pm $0.63,1.75 \pm 0.07,1.26 \pm 0.05$ respectively $)(\mathrm{P}<0.001)$. Additionally, data analysis demonstrated significant differences between the treatment modalities in the length of the extension of the junctional epithelium along the root surface $(0.87 \pm 0.46,0.0 \pm 0.0$ for group I \& II respectively) $(\mathrm{P}<0.01)$ (Table 1).

\section{Discussion}

The use of different regenerative approaches in the treatment of periodontal defects has demonstrated a variable clinical result $[14,15]$. Some techniques have been used in association, aiming to increase their effect on periodontal regeneration $[16,17]$.

Recently, strontium ranelate anti-osteoporotic drug shows considerable interest in investigations looking to improve implant osseointegration [18]. It has been shown to prevent bone loss by maintaining bone formation at a high level and inhibiting bone resorption [3]. Furthermore, treatment with SrRan is not associated with osteonecrosis of the jaw; this represents a distinct advantage over bisphosphonate [18].

Since histological evaluation remains the only reliable method to determine the efficacy of periodontal therapies [19], therefore, the present study was employed in an attempt to evaluate the healing of surgically created intrabony periodontal defects in dogs after treatment with strontium ranelate $2 \%$ gel in a collagen sponge histological and histomorphometrically.

It is well accepted that healing of intrabony defects is positively correlated to the number of bone walls limiting the defect. One and three wall intrabony defects appear to be reproducible models to evaluate candidate technologies for periodontal regeneration [20].

The box-type one-wall intrabony defect model in dogs is a wellestablished model and has been used to evaluate the effect of particular biomaterials on periodontal regeneration [20,21]. Therefore, in this study, one-wall defects with only an interproximal bony wall which had minimal self-healing capacities were used. The standardized surgical defect size in acute models allows equal conditions for healing. In addition, this defect is less time and money consuming [22]. Reference notches $(\mathrm{N} 1 \& \mathrm{~N} 2)$ were made at the cemento-enamel junction and at the base of defect respectively to act as a guide for histologic evaluation. Furthermore, this model is suitable for investigation of new material, drugs or substances to determine their safety and establish the risk of adverse reactions during periodontal repair process [23].

Isidor et al. [24] demonstrated that, there is no difference regarding the reformation of connective tissue attachment whether this has been lost because of periodontal disease or mechanically removed (acute defect). To apply gel phase strontium into one-wall intrabony defect, a carrier is required; therefore, collagen sponge was used as a carrier. Its fibrillar mesh-work structure makes it a conductive scaffold for colonization by host cells from periodontal ligament, and it also acts as a chemotactic to periodontal ligament cells $[25,26]$.

In order to obtain the desired results, the necessary minimum observation period needs to be determined. It was reported that at approximately 6 weeks, a considerable amount of new bone fill was obtained [27]. Choi et al. [28], reported that no differences in bone regeneration by Bone Morphogenic Protein (BMP) were noted between an 8- and 24 week interval, hence in this study we selected 12 weeks to evaluate the healing.

In this study, we observed that the use of a SrRan did not cause any undesirable reaction, showing biocompatibility with both connective and bone tissues. No foreign body reactions indicating toxicity were observed, which confirmed the safety of SrRan.

Strontium treated group showed an excellent healing that exhibit new bone, cementum and functionally oriented periodontal ligament as compared to the control treated group. Strontium treated group showed an excellent healing that exhibit new bone, cementum and functionally oriented periodontal ligament as compared to the control group. This was confirmed by the histomorphometric findings that demonstrated that the sites treated with strontium showed bigger amounts of new bone and cementum ( $3.89 \pm 0.09,3.42 \pm 0.75$ respectively) when compared to the control sites $(1.17 \pm 0.63,1.75 \pm 0.07$ respectively).

This tremendous regeneration potential of strontium may be related to reduction of osteoclast number by regulating the Production of Osteoprotegerin (OPG) and Receptor Activator of Nuclear Factor K-B Ligand (RANKL). Low doses of SrRan were found to increase OPG expression and production and to decrease RANKL expression by osteoblasts in vitro $[29,30]$.

Another possible mechanism by which SrRan may control osteoclast activity and life span is via activation of the Calcium-Sensing Receptor (CaSR). Strontium acts on the CaSR as a full agonist with lower affinity than calcium [31,32]. There is some evidence that osteoclast precursor cells and osteoclasts express the parathyroid CaSR $[33,34]$. Interestingly, this receptor mediates the increased osteoclast apoptosis induced by SrRan [35]. Finally, both calcium and strontium were found to act on osteoclast precursor cells via the CaSR [34,36]. 
Citation: Elgendy EA, Shoukheba MYM (2012) Histological and Histomorphometric Study of the Effect of Strontium Ranelate on the Healing of OneWall Intrabony Periodontal Defects in Dogs. J Cytol Histol 3: 161. doi:10.4172/2157-7099.1000161

In addition, strontium, decreased the expression of sclerostin, an osteocyte specific secreted protein that acts as a negative regulator of bone formation by inhibiting canonical Wnt signaling, hence strentium expected to increase canonical Wnt signalling that stimulates osteoblastic proliferation, differentiation and function [37]. Moreover, Gulhan et al. [38] showed that the treatment with strontium ranelate for 6 months results in increased serum IGF-1 levels, which may suggest that IGF-1 may be a mediator in the antiresorptive effect of SrRan.

In the present study, a regular layer of cementum could be observed on the root surface in the test defects (strontium treated group), with inhibition of apical migration of the junctional epithelium. This layer was thinner coronally, but there was insertion of functionally oriented connective tissue fibers indicating a new connective tissue attachment. The new insertion could be identified by the existence of cementum deposition with connective fibers functionally attached and consequent inhibition of apical migration of the junctional epithelium. This newly formed insertion was greater in the defects treated with strontium gel than in the control treated sites, which showed repair by long junctional epithelium and more connective tissue adhesion as indicated by histomorphometric measurements $(0.87 \pm 0.46)$.

This can be explained by the creation of space by collagen sponge allowing migration of periodontal ligament cells and bone cells on the denuded root surface which is necessary for periodontal regeneration [39]. Strontium ranelate may stimulate a rapid formation of a connective tissue seal that is supposed to have the ability to block the epithelium migration and allow for repopulation of the previously contaminated area by periodontal ligament cells $[40,41]$.

In conclusion, the strontium ranelate tested in this experiment had better healing potential than placebo (control) only. The strontium ranelate showed a promising inhibition of apical migration of the junctional epithelium and consequently the greater cementum deposition on the radicular surface of one-wall intrabony defects in dogs. Future investigations should evaluate this potential comparatively or together with other grafting materials, regenerative techniques and biological modifiers, as well as assess the longitudinal stability of the new attachment.

\section{References}

1. Sakata J, Abe H, Ohazama A, Okubo K, Nagashima C, et al. (2006) Effects of Combined Treatment with Porous Bovine Inorganic Bone Graftsand Bilayer Porcine Collagen Membrane on Refractory One-Wall Intrabony Defects. Int J Periodontics Restorative Dent 26: 161-169.

2. Page RC (1993) Periodontal therapy: prospects for the future. J Periodontol 64: 744-753

3. Meunier PJ, Roux C, Seeman E, Ortolani S, Badurski JE, et al. (2004) The effects of strontium ranelate on the risk of vertebral fracture in women with postmenopausal osteoporosis. N Engl J Med 350: 459-468.

4. Henrotin Y, Labasse A, Zheng SX, Galais P, Tsouderos Y, et al. (2001) Strontium ranelate increases cartilage matrix formation. J Bone Miner Res 16: 299-308.

5. Alexandersen P, Karsdal MA, Qvist P, Reginster JY, Christiansen C (2007) Strontium ranelate reduces the urinary level of cartilage degradation biomarker CTX-II in postmenopausal women. Bone 40: 218-222.

6. Choudhary S, Halbout P, Alander C, Raisz L, Pilbeam C (2007) Strontium ranelate promotes osteoblastic differentiation and mineralization of murine bone marrow stromal cells: involvement of prostaglandins. J Bone Miner Res 22: $1002-1010$

7. Zhu LL, Zaidi S, Peng Y, Zhou H, Moonga BS, et al. (2007) Induction of a program gene expression during osteoblast differentiation with strontium ranelate. Biochem Biophys Res Commun 355: 307-311.

8. Takahashi N, Sasaki T, Tsouderos Y, Suda T (2003) S 12911-2 inhibits osteoclastic bone resorption in vitro. J Bone Miner Res. 18: 1082-1087.
9. Kendler DL (2006) Strontium ranelate--data on vertebral and nonvertebral fracture efficacy and safety: mechanism of action. Curr Osteoporos Rep 4: 3439.

10. Delannoy P, Bazot D, Marie PJ (2002) Long-term treatment with strontium ranelate increases vertebral bone mass without deleterious effect in mice. Metabolism 51: 906-911

11. Ammann P, Shen V, Robin B, Mauras Y, Bonjour JP, et al. (2004) Strontium ranelate improves bone resistance by increasing bone mass and improving architecture in intact female rats. J Bone Miner Res 19: 2012-2020.

12. Buehler J, Chappuis P, Saffar JL, Tsouderos Y, Vignery A (2001) Strontium ranelate inhibits bone resorption while maintaining bone formation in alveolar bone in monkeys (Macaca fascicularis). Bone 29: 176-179.

13. Kim TG, Wikesjö UM, Cho KS, Chai JK, Pippig SD, et al. (2009) Periodontal wound healing/regeneration following implantation of recombinant human growth/differentiation factor-5 (rhGDF-5) in an absorbable collagen sponge carrier into one-wall intrabony defects in dogs: a dose-range study. J Clin Periodontol 36: 589-597.

14. Guimarães Mdo C, Passanezi E, Sant'ana AC, Greghi SL (2004) Pool of bovine morphogenetic proteins and guided tissue regeneration in the treatment of intrabony periodontal defects: I-Clinical measurements. J Appl Oral Sci 12 70-77.

15. Chambrone D, Pasin IM, Conde MC, Panutti C, Carneiro S, et al. (2007) Effect of enamel matrix proteins on the treatment of intrabony defects: a split-mouth randomized controlled trial study. Braz Oral Res 21: 241-246.

16. Fernandes JM, Rego RO, Spolidorio LC, Marcantonio RA, Marcantonio Júnio E, et al. (2005) Enamel matrix proteins associated with GTR and bioactive glass in the treatment of class III furcation in dogs. Braz Oral Res 19: 169-175.

17. Marx RE, Carlson ER, Eichstaedt RM, Schimmele SR, Strauss JE, et al. (1998) Platelet-rich plasma: Growth factor enhancement for bone grafts. Oral Surg Oral Med Oral Pathol Oral Radiol Endod 85: 638-646.

18. Maïmoun L, Brennan TC, Badoud I, Dubois-Ferriere V, Rizzoli R, et al. (2010) Strontium ranelate improves implant osseointegration. Bone 46: 1436-1441.

19. Brunsvold MA, Mellonig JT (1993) Bone grafts and periodontal regeneration. Periodontol 2000 1: 80-91.

20. Kim CS, Choi SH, Chai JK, Cho KS, Moon IS, et al. (2004) Periodontal repair in surgically created intrabony defects in dogs: influence of the number of bone walls on healing response. J Periodontol 75: 229-235.

21. Kim CS, Um YJ, Chai JK, Cho KS, Moon IS, et al. (2011) A canine model for histometric evaluation of periodontal regeneration. Periodontol 2000 56: 209226 .

22. Caton J, Greenstein G, Zappa U (1994) Synthetic bioabsorbable barrier for regeneration in human periodontal defects. J Periodontol 65: 1037-1045.

23. Selvig KA (1994) Discussion: animal models in reconstructive therapy. $J$ Periodontol 65: 1169-1172.

24. Isidor F, Karring T, Nyman S, Lindhe J (1985) New attachment-reattachment following reconstructive periodontal surgery. J Clin Periodontol 12: 728-735.

25. Blumenthal N, Sabe T, Barrington E (1986) Healing responses to grafting of combined collagen-decalcified bone in periodontal defects in dogs. J Periodontol 57: 84-90.

26. Pitaru S, Tal H, Soldinger M, Grosskopf A, Noff M (1988) Partial regeneration of periodontal tissues using collagen barriers. Initial observations in the canine. J Periodontol 59: 380-386

27. Polson AM, Caton J (1982) Factors influencing periodontal repair and regeneration. J Periodontol 53: 617-625

28. Choi SH, Kim CK, Cho KS, Huh JS, Sorensen RG, et al. (2002) Effect of recombinant human bone morphogenetic protein-2/absorbable collagen sponge (rhBMP-2/ACS) on healing in 3-wall intrabony defects in dogs. J Periodontol 73: 63-72.

29. Atkins GJ, Welldon KJ, Halbout P, Findlay DM (2009) Strontium ranelate treatment of human primary osteoblasts promotes an osteocyte-like phenotype while eliciting an osteoprotegerin response. Osteoporos Int 20: 653-664.

30. Brennan TC, Rybchyn MS, Green W, Atwa S, Conigrave AD, et al. (2009) Osteoblasts play key roles in the mechanisms of action of strontium ranelate. Br J Pharmacol 157: 1291-1300. 
Citation: Elgendy EA, Shoukheba MYM (2012) Histological and Histomorphometric Study of the Effect of Strontium Ranelate on the Healing of OneWall Intrabony Periodontal Defects in Dogs. J Cytol Histol 3: 161. doi:10.4172/2157-7099.1000161

Page 6 of 6

31. Brown EM (2003) Is the calcium receptor a molecular target for the actions of strontium on bone? Osteoporos Int. 14 (Suppl 3): S25-S34

32. Coulombe J, Faure H, Robin B, Ruat M (2004) In vitro effects of strontium ranelate on the extracellular calcium-sensing receptor. Biochem Biophys Res Commun 323: 1184-1190.

33. Chang W, Tu C, Chen TH, Komuves L, Oda Y, et al. (1999) Expression and signal transduction of calcium-sensing receptors in cartilage and bone. Endocrinology 140: 5883-5893.

34. Mentaverri R, Yano S, Chattopadhyay N, Petit L, Kifor O, et al. (2006) The calcium sensing receptor is directly involved in both osteoclast differentiation and apoptosis. FASEB J 20: 2562-2564.

35. Hurtel-Lemaire AS, Mentaverri R, Caudrillier A, Cournarie F, Wattel A, et al. (2009) The calcium-sensing receptor is involved in strontium ranelate-induced osteoclast apoptosis. New insights into the associated signaling pathways. $J$ Biol Chem 284: 575-584.

36. Caudrillier A, Hurtel-Lemaire AS, Wattel A, Cournarie F, Godin C, et al. (2010) Strontium ranelate decreases RANKL induced osteoclastic differentiation in vitro: involvement of the calcium sensing receptor. Mol Pharmacol. 78: 569-576.
37. Rybchyn MS, Slater M, Conigrave AD, Mason RS (2011) An Akt-dependent increase in canonical Wnt signaling and a decrease in sclerostin protein levels are involved in strontium ranelate-induced osteogenic effects in human osteoblasts. J Biol Chem 286: 23771-23779.

38. Gulhan I, Bilgili S, Gunaydin R, Gulhan S, Posaci C (2008) The effect of strontium ranelate on serum insulin like growth factor-1 and leptin levels in osteoporotic post-menopausal women: a prospective study. Arch Gynecol Obstet 278: 437-441.

39. Nyman S, Lindhe J, Karring T (1989) Reattachment- new attachment In: Lindhe J (ed). Textbook of Clinical Periodontology. Copenhagen: Munksgaard.

40. Hench LL, Paschall HA (1974) Histochemical responses at a biomaterial's interface. J Biomed Mater Res 8: 49-64.

41. Gräber HG, Conrads G, Wilharm J, Lampert F (1999) Role of interactions between integrins and extracellular matrix components in healthy epithelia tissue and establishment of a long junctional epithelium during periodontal wound healing: a review. J Periodontol 70: 1511-1522. 